\title{
CENTRAL COMPOSITE DESIGN FOR FORMULATION AND OPTIMIZATION OF LONG-ACTING INJECTABLE (LAI) MICROSPHERES OF PALIPERIDONE PALMITATE
}

\author{
SANDIP MALI*, NISHANT OZA
}

Department of Pharmaceutical Science, Research, Development and Innovation Centre (RDIC), C. U. Shah University, Wadhwan City, Surendranagar 363030, Gujarat, India

Email: sandiplmali@rediffmail.com

Received: 03 Jun 2021, Revised and Accepted: 03 Aug 2021

\begin{abstract}
Objective: The aim of the present study was to optimize long-acting injectable (LAI) microspheres of Paliperidone palmitate (PP) for treatment of schizophrenia using face-centered central composite design (FC-CCD).

Methods: In this study, poly lactic-co-glycolic acid (PLGA) based LAI microspheres of paliperidone palmitate (PP) were formulated by using FCCCD. LAI microspheres were developed by using oil in water $(\mathrm{O} / \mathrm{W})$ emulsion solvent evaporation technique. On the basis of preliminary trials, FCCCD was employed to check effect of independent variables such as drug polymer ratio $\left(\mathrm{X}_{1}\right)$, homogenization speed $\left(\mathrm{X}_{2}\right)$ and rate of addition $\left(\mathrm{X}_{3}\right)$. While mean particle size $\left(\mathrm{Y}_{1}\right)$, drug loading $\left(\mathrm{Y}_{2}\right)$, entrapment efficiency $\left(\mathrm{Y}_{3}\right)$, burst release $\left(\mathrm{Y}_{4}\right)$, and drug release on day $60\left(\mathrm{Y}_{5}\right)$ were considered as dependent variables and statistically evaluation performed by using design expert 12 software. Morphology of prepared microspheres was studied by using the scanning electron microscopy (SEM) technique, while particle size was analyzed by laser diffraction technique. In vitro drug release studies were performed using a controlled temperature shaking water bath apparatus. Fourier transforms infrared spectroscopy (FTIR) and differential scanning calorimetric (DSC) study were performed to analyze any changes in crystal behavior or to detect any chemical bonding between ingredients. ${ }^{13} \mathrm{C}$ NMR and ${ }^{1} \mathrm{H}$ NMR techniques were used to analyze end-capping and monomer ratio in developed microspheres.
\end{abstract}

Results: The factorial batches mean particle size was found to be $38 \mu \mathrm{m}$ to $104 \mu \mathrm{m}$ and drug loading were found between $27.2 \%$ to $47.2 \%$. Mathematical modelling of drug release kinetics revealed that near zero-order drug release of checkpoint formulations. Endcap analysis and molar ratio of formulated microspheres were found to be ester end cap and $~ 75: 25$, respectively. Morphologically all the prepared samples were found to be spherical in shape and smooth surface. FTIR data showed no significant interactions occurred between drug and excipients. The actual responses of checkpoint formulations were observed within $5 \%$ variation of predicted values.

Conclusion: The prepared microspheres showed promising results of morphology, particle size, drug loading, entrapment efficiency, burst release and drug release on day 60 . The successful predictive designs models were achieved from employed FC-CCD.

Keywords: Central composite design, Face centered, PLGA, Long-acting, Injectable, Microspheres, Schizophrenia, Paliperidone palmitate

(C) 2021 The Authors. Published by Innovare Academic Sciences Pvt Ltd. This is an open access article under the CC BY license (https://creativecommons.org/licenses/by/4.0/) DOI: https://dx.doi.org/10.22159/ijap.2021v13i5.42297. Journal homepage: https://innovareacademics.in/journals/index.php/ijap

\section{INTRODUCTION}

Long-acting injectable (LAI) dosage forms are becoming choice of medical practitioners to combat diseases which need long-term therapy for management and cure [1]. LAI's are being used for clinical management of various disease conditions like cancer, schizophrenia, opioid intolerance; diabetes, acromegaly, osteoarthritis etc [2]. Many platform technologies are employed in development of LAIs such as oil based suspensions $[3,4]$, polymeric particulate systems [5, 6], polymer gels [7], implant [8, 9] and particulate suspensions [10]. Continuous research is ongoing to cater the unmet need of medical field for newer disease conditions and dosage designs.

Schizophrenia is mental disorder that adversely affects thoughts and daily life of patient. Schizophrenia is associated with impact on health, social, occupational, and economics. Sleep, hostility, depression and body mass index may be targeted to improve quality of life [11].

Numerous treatment options available for schizophrenia include oral dosages, injectable as well as long-acting injectable (LAI) as first generation and second-generation antipsychotics. Antipsychotic medications are also classified based on their mechanism of action as typical and atypical antipsychotics. Compared to typical antipsychotics, atypical induce fewer extrapyramidal side effects, but the exact neurobiological substrate of this difference is still unknown [12,13]. Antipsychotic drugs are available in market in various dosage designs researched based on need of patients being treated. Long-acting antipsychotic drugs has proven benefits in terms of patient compliance, guaranteed adherence to drug treatment, relapse prevention and clinical outcomes. Long-acting antipsychotics are becoming the preferred choice for maintenance therapy for schizophrenia. Long-acting injectable antipsychotics of aripiprazole, fluphenazine decanoate, haloperidol decanoate, risperidone, paliperidone, olanzapine pamoate etc. are available in market for intramuscular administrations as microspheres, suspensions, oily suspensions etc. [14-16].

Poly-lactic-co-glycolic acid (PLGA) is aliphatic polymer with a polyester backbone that is formed through the copolymerization of lactic and glycolic acid monomers. Engineering in lactic acid and glycolic acid ratio provides different release characteristics to the delivery system $[17,18]$. It is preferred because of its biocompatibility, biodegradability and mechanical strength and continues to be used to develop new controlled release systems [19].

Paliperidone palmitate is most recent second-generation atypical antipsychotic approved in the USA and the EU. Paliperidone palmitate is practically insoluble in water, has low partition coefficient ( $\log \mathrm{P}=1.8$ ). It has limited oral bioavailability of $28 \%$ [20, 21]. In order to achieve greater control over drug release from long acting release system, an attempt has been made to formulate paliperidone palmitate drug in a long-acting PLGA based polymeric platform using design of experiment methodology. Advantages of long-acting paliperidone palmitate microspheres are less frequent dosing, greater compliance to treatment, reduced relapse and improved bioavailability.

\section{MATERIALS AND METHODS}

\section{Materials}

PLGA Resomer ${ }^{\circledR}$ RG750S, inherent viscosity 0.8 to $1.2 \mathrm{dl} / \mathrm{g}$ ) was obtained from Boehringer-Ingelheim. Paliperidone palmitate (PP) API was received from Neuland Pharma, India. Poly (vinyl alcohol) (PVA 8-88) 
was gift sample obtained from Merck KGgA, Germany. Methylene chloride (DCM), methanol (HPLC grade), ortho-phosphoric acid (HPLC grade), acetonitrile (HPLC grade) were of avantor performance materials, USA. Milli-Q water was used for all chromatography studies. Water for Injection used for all formulation activities.

\section{Methods}

\section{Preparation of long-acting injectable (LAI) microspheres}

Paliperidone palmitate-loaded LAI microspheres were developed by the oil-in-water $(0 / \mathrm{W})$ emulsion solvent evaporation technique [22, 23]. In this method, weighed quantity of Paliperidone palmitate was dissolved in dichloromethane by vortexing (Vortex shaker, Remi, India) and cool to $5{ }^{\circ} \mathrm{C}$. PLGA was added and dissolved in drug solution by vortexing to form organic Phase. Polyvinyl alcohol (Molecular weight: 30-70 KD) was added and dissolved in $2000 \mathrm{ml}$ of water for injection by stirring (Eurostar 20, IKA Germany) at 750 $\mathrm{rpm}$ for $6 \mathrm{~h}$ and cool the PVA solution to $5{ }^{\circ} \mathrm{C}$. Emulsification was carried out by in-line high shear homogenization (Megatron MT300, Kinematica AG, Switzerland). Oil phase was added to the aqueous phase through the addition port of homogenizer by a peristaltic pump (Remi, India) at specific rate of addition and homogenization speed. Then, Emulsion was transferred to 5 liter of aqueous PVA solution and stirred at $300 \mathrm{rpm}$ under vacuum for $8 \mathrm{~h}$ to evaporate methylene chloride and hardening of microspheres. Microspheres were separated by means of filtration using Whatman paper. Microspheres were washed three times using 3-liter water for injection. Microspheres were dried by freeze-drying.

\section{Experimental design}

Face centred central composite design (FC-CCD) was used to optimize process parameters in this study. The details of independent and dependant variables used in this design are shown in table 1. In this, design three independent factors were evaluated, each at two levels and experimental trials were performed for seventeen formulations including 3 center points as shown in table 2. There were four major factors affecting the formulation drug: polymer ratio $\left(\mathrm{X}_{1}\right)$, homogenization speed $\left(\mathrm{X}_{2}\right)$ and rate of addition $\left(\mathrm{X}_{3}\right)$. While mean particle size $\left(\mathrm{Y}_{1}\right)$, drug loading $\left(\mathrm{Y}_{2}\right)$, entrapment efficiency $\left(\mathrm{Y}_{3}\right)$, burst release $\left(\mathrm{Y}_{4}\right)$, drug release on day $60\left(\mathrm{Y}_{5}\right)$ were considered as dependent variables. Design expert version 12 (StatEase, USA). The statistical software was used for data treatment and generating visualization. Effects were considered statistically significant if value of $\mathrm{P} \leq 0.05$.

Table 1: Process variables in experiments

\begin{tabular}{llll}
\hline Factor & Process parameter & Level \\
\cline { 3 - 3 } & & Low & $\mathbf{\text { High }}$ \\
\hline \multicolumn{2}{l}{ Independent variables } & \\
X1 & Drug: Polymer ratio $(\%)$ & $1: 2$ & 1000 \\
X2 & Homogenization speed (rpm) & 4 & 4000 \\
X3 & Rate of addition $(\mathrm{mL} / \mathrm{min})$ & \\
Dependant variables & & \\
Y1 & Mean particle size $(\mu)$ & \\
Y2 & Drug Loading $(\%)$ & \\
Y3 & Entrapment Efficiency $(\%)$ & \\
Y4 & Burst release $(\%)$ & \\
Y5 & Drug release at day $60(\%)$ & \\
\hline
\end{tabular}

Table 2: Independent and dependant variables-face centred central composite design (FC-CCD)

\begin{tabular}{|c|c|c|c|c|c|c|c|c|c|c|c|c|c|}
\hline \multirow[t]{3}{*}{ Run } & \multirow{2}{*}{\multicolumn{2}{|c|}{$\begin{array}{l}\text { Independent } \\
\text { variables }\end{array}$}} & & \multicolumn{10}{|c|}{ Dependant variables } \\
\hline & & & & \multicolumn{5}{|c|}{ Actual } & \multicolumn{5}{|c|}{ Predicted } \\
\hline & $\mathbf{X}_{1}$ & $\mathbf{X}_{2}$ & $\mathbf{X}_{3}$ & $Y_{1}(\mu \mathrm{m})$ & $Y_{2}(\%)$ & $Y_{3}(\%)$ & $Y_{4}(\%)$ & Y5 (\%) & $Y_{1}(\mu \mathrm{m})$ & $Y_{2}(\%)$ & $Y_{3}(\%)$ & $Y_{4}(\%)$ & Y5 (\%) \\
\hline 1 & 41.66 & 2500 & 4 & 78 & 36.4 & 87.3 & 0.67 & 64 & 75.9 & 35.7 & 85.9 & 1.05 & 70.4 \\
\hline 2 & 50 & 2500 & 10 & 67 & 41.1 & 82.2 & 1.04 & 99 & 61.8 & 41.3 & 82.8 & 1.39 & 86.6 \\
\hline 3 & 50 & 1000 & 4 & 92 & 47.2 & 94.4 & 0.4 & 56 & 94.8 & 47.3 & 94.8 & 0.19 & 63.9 \\
\hline 4 & 33.33 & 4000 & 16 & 51 & 24.1 & 72.3 & 2.12 & 87 & 48.8 & 24.0 & 72.1 & 2.25 & 92.9 \\
\hline 5 & 41.7 & 2500 & 10 & 66 & 35.5 & 85.2 & 1.28 & 81 & 67.0 & 35.3 & 84.9 & 1.19 & 78.5 \\
\hline 6 & 50 & 1000 & 16 & 68 & 43.2 & 86.4 & 0.98 & 86 & 68.1 & 42.8 & 85.5 & 0.99 & 80.0 \\
\hline 7 & 50 & 4000 & 4 & 46 & 39.4 & 78.8 & 3.27 & 96 & 46.2 & 39.3 & 78.5 & 3.16 & 93.4 \\
\hline 8 & 33.33 & 1000 & 4 & 104 & 31.2 & 93.6 & 0.09 & 46 & 104.7 & 31.3 & 93.7 & 0.04 & 47.7 \\
\hline 9 & 41.7 & 2500 & 10 & 63 & 35.2 & 84.4 & 1.44 & 86 & 67.0 & 35.3 & 84.9 & 1.19 & 78.5 \\
\hline 10 & 33.33 & 2500 & 10 & 74 & 28.2 & 84.6 & 0.69 & 72 & 72.2 & 27.7 & 83.1 & 0.58 & 70.3 \\
\hline 11 & 41.6 & 2500 & 16 & 54 & 31.4 & 75.3 & 1.79 & 85 & 58.1 & 31.7 & 76.0 & 1.65 & 86.5 \\
\hline 12 & 50 & 4000 & 16 & 38 & 35.2 & 70.4 & 3.82 & 98 & 37.9 & 35.2 & 70.4 & 3.76 & 109.3 \\
\hline 13 & 33.33 & 1000 & 16 & 77 & 27.2 & 81.6 & 0.65 & 67 & 77.4 & 27.3 & 82.0 & 0.69 & 63.6 \\
\hline 14 & 33.33 & 4000 & 4 & 57 & 27.2 & 81.6 & 1.9 & 81 & 57.6 & 27.6 & 82.7 & 1.83 & 76.9 \\
\hline 15 & 41.66 & 1000 & 10 & 92 & 39.6 & 95.0 & 0.37 & 54 & 86.3 & 39.7 & 94.9 & 0.52 & 63.77 \\
\hline 16 & 41.66 & 2500 & 10 & 64 & 34.9 & 83.7 & 1.35 & 82 & 67.0 & 35.3 & 84.9 & 1.19 & 78.5 \\
\hline 17 & 41.66 & 4000 & 10 & 48 & 34.4 & 82.5 & 2.7 & 94 & 47.7 & 34.1 & 81.9 & 2.79 & 93.1 \\
\hline
\end{tabular}

$\mathrm{X}_{1}=1: 1$ is $50 \%: 50 \%, X_{1}=1: 1.5$ is $40 \%: 60 \%, X_{1}=1: 2$ is $33.33 \%: 66.66 \%$

\section{Morphology}

The surface morphology of formulated microspheres was examined by scanning electron microscopy (SEM) (Hitachi S-3700N, Japan) at $15 \mathrm{KV}$ with an appropriate magnification.

\section{Particle size and size distribution}

Particle size and Particle size distribution of the microspheres were determined using a laser diffraction technique (Malvern 3000,
Malvern, UK). The particles were suspended in $0.1 \%$ Tween 20 and counted using a laser sensor. The average particle size was expressed as volume mean diameter in microns $(\mu \mathrm{m})$.

\section{Drug loading}

Drug loading was determined by using HPLC technique. $62.4 \mathrm{mg}$ of paliperidone palmiate-loaded PLGA microspheres added in $100 \mathrm{ml}$ volumetric flask. Add the $80 \mathrm{ml}$ diluent (Isopropyl alcohol, 
acetonitrile, water and ortho-phosphoric acid in the ratio of $(50: 25: 25: 0.1, \% \mathrm{v} / \mathrm{v})$ in a volumetric flask and sonicate for $5 \mathrm{~min}$. Make up the volume upto $100 \mathrm{ml}$ with diluent and mix well. Solution was filtered through PVDF $0.45 \mu \mathrm{m}$ syringe filter and the drug concentration was determined using HPLC system equipped with UV absorbance detector ( $280 \mathrm{~nm}$ wavelength). Mobile phase consist of a mixture of buffer pH-2.2 and acetonitrile $(25: 75, \% \mathrm{v} / \mathrm{v})$. Intersil C18 $(4.6 \mathrm{~mm} \times 250 \mathrm{~cm}, 5 \mu)$ analytical column was used with flow rate of $1.5 \mathrm{ml} / \mathrm{min}$ and injection volume of $20 \mu \mathrm{l}$. Chromatographs were analysed by empower chromatography system.

\section{In vitro release testing}

In this study, weighed quantity of microspheres (i.e. $6 \mathrm{mg}$ drug equivalent) was placed in flat bottom conical flasks filled with 200 $\mathrm{ml}$ phosphate buffer saline of $\mathrm{pH} 7.4$ with $0.02 \%$ polysorbate 20 . Conical flasks were placed in a temperature-controlled shaking water bath [24](SW23, Julabo, Germany) set at $70 \pm 2 \mathrm{rpm}, 37 \pm 0.5^{\circ} \mathrm{C}$. At predefined sampling points, $1.5 \mathrm{ml}$ of release sample was withdrawn and was replaced with fresh release medium. Testing was performed in triplicate $(n=3)$. Drug concentrations in release samples were quantified spectrophotometrically at $280 \mathrm{~nm}$ for Paliperidone (Shimadzu UV 1800, Shimadzu Japan).

\section{Differential scanning calorimeter (DSC) analysis}

Thermal behaviour and glass transition temperature of paliperidone palmitate API, PLGA 75:25, Physical Mixture (1:1), Placebo and formulated microspheres using differential scanning DSC (DSC60 Shimadzu, Japan). Samples were heated at a rate of $1{ }^{\circ} \mathrm{C} / \mathrm{min}$ from $25{ }^{\circ} \mathrm{C}$ to $140^{\circ} \mathrm{C}$. The thermograms were analysed to determine the glass transition temperatures and melting point.

\section{Fourier transform infrared (FT-IR)}

FT-IR spectrum of Paliperidone palmitate API, PLGA 75:25, physical mixture (1:1), placebo and formulated microspheres were measured in the solid-state as potassium bromide dispersion using a FT-IR spectrometer-430 (Shimadzu 8400S, JAPAN). Each sample was properly grounded in mortar and pestle with potassium bromide in ratio of 1:100 (sample: Potassium Bromide). Powders were compressed into discs with the help of hydraulic compression press at 12 tonnes for $5 \mathrm{~min}$. The FT-IR scan range was ranging from 4000 to $500 \mathrm{~cm}^{-1}$.

\section{Proton nuclear magnetic resonance ( $\left.{ }^{1} \mathrm{H}-\mathrm{NMR}\right)$}

${ }^{1} \mathrm{H}$-NMR spectroscopy analysis was performed to determine the Lactide: Glycolide (L: G) molar ratio of the PLGA 75:25 and formulated microspheres. Sample was dissolved in deuterated chloroform (CDCl3) solvent $(0.9 \mathrm{ml})$ at $500 \mathrm{MHz}$. Peak intensities at $5.2 \mathrm{ppm}$ and $4.8 \mathrm{ppm}$ was considered for proton counting. The integration at $5.2 \mathrm{ppm}$ represents a single $\mathrm{H}$ of Lactide, while the integration at $4.8 \mathrm{ppm}$ represents $2 \mathrm{H}$ of Glycolide. The mole fractions of Lactide (ML) and Glycolide (MG) were estimated from peak integration (P) of each component marked with ' $\mathrm{L}$ ' for Lactide and ' $G$ ' for Glycolide, respectively [25].

$$
\begin{aligned}
& M G=\frac{P G / 2}{P L+\left(\frac{P G}{2}\right)} \\
& M L=\frac{P L}{P L+\left(\frac{P G}{2}\right)}
\end{aligned}
$$

\section{Carbon-13 nuclear magnetic resonance ( ${ }^{13} \mathrm{C}$ NMR)}

End group capping of PLGA and prepares microspheres were analysed using ${ }^{13} \mathrm{C}$ NMR [25]. Total of 12,000 scans were acquired over $12.5 \mathrm{~h}$. Ester end-cap was confirmed by the existence of a peak at $\sim 14 \mathrm{ppm}$, which correlates to an end-methyl unit on a long alkyl chain.

\section{RESULTS AND DISCUSSION}

\section{Mean particle size $\left(\mathrm{Y}_{1}\right)$}

Particle size analysis was performed by the principle of laser diffraction and results are represented in table 2. Composition and manufacturing process parameters were observed to show an impact on the particle size and particle size distribution of prepared microspheres. ANOVA data in table 3 for response mean particle size (D50) depicts that factor $X_{1}$ (Drug: Polymer ratio), $X_{2}$ (Homogenization speed) and $X_{3}$ (rate of addition) are statistically significant main effects at level 0.05 . Two-way interaction of $\mathrm{X}_{2}$ (Homogenization speed) and $\mathrm{X}_{3}$ (rate of addition) found to significantly impacting mean particles size at level 0.05 . The lack of fit F-value of 6.40 implies that the lack of fit is not significant relative to pure error. The predicted $\mathrm{R}^{2}$ of 0.9316 is in reasonable agreement with an adjusted $\mathrm{R}^{2}$ of 0.9609 i.e. the difference is less than 0.2. The signal-to-noise ratio of 29.536 indicates adequate signal. Regression analysis data for response mean particle size showed in table 4 .

DOE model for Mean Particle Size (D50):

Mean Particle Size (D50, micron) $=150.75815-5.20 \mathrm{X}_{1}-19.30 \mathrm{X}_{2}-$ $8.90 \mathrm{X}_{3} 0.3750 \mathrm{X}_{1} * \mathrm{X}_{2}+0.1250 \mathrm{X}_{1} * \mathrm{X}_{3}+4.63 \mathrm{X}_{2} * \mathrm{X}_{3}$

Contour plot and three-dimensional surface plot of mean particle size (D50) shows the impact of variation of factor values of on mean particle size (fig. 1). The homogenization speed $\left(\mathrm{X}_{2}\right)$ and rate of addition $\left(\mathrm{X}_{3}\right)$ of organic phase to aqueous phase found to significantly impacting the mean particle size of prepares microspheres. The increase in homogenization speed $\left(\mathrm{X}_{2}\right)$ and rate of addition $\left(\mathrm{X}_{3}\right)$ reduces the mean particle size of microspheres (fig. 1).
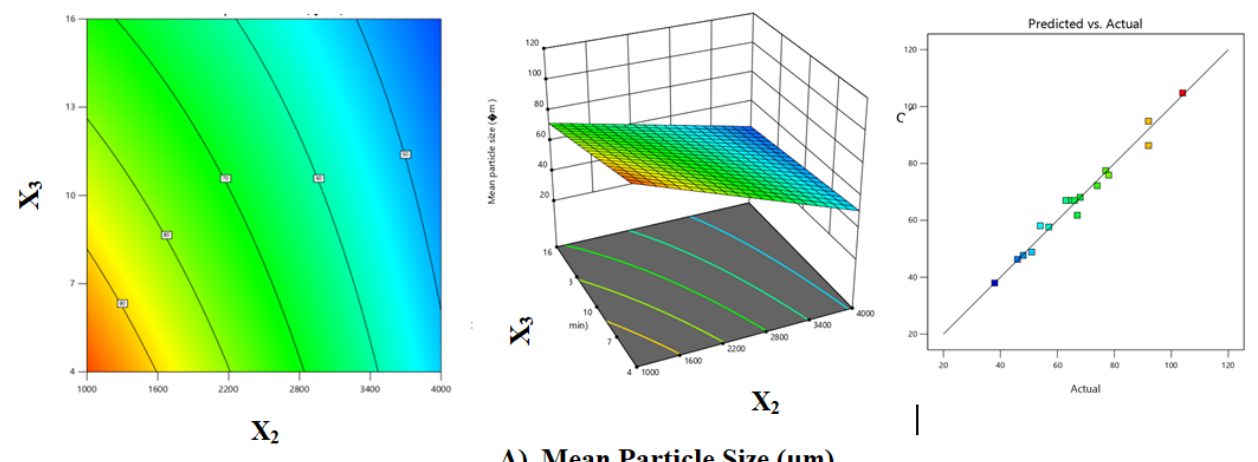

A) Mean Particle Size $(\mu \mathrm{m})$

Fig. 1: Graphical representation of data-mean particle size $\left(\mathrm{Y}_{1}\right)$

Batches with homogenization speed of $1000 \mathrm{rpm}$ and $4000 \mathrm{rpm}$ showed varied particle size of microspheres. Homogenization speed of $1000 \mathrm{rpm}$ resulted in microspheres with the mean particle size of $92 \mu \mathrm{m}, 68 \mu \mathrm{m}$, $104 \mu \mathrm{m}, 77 \mu \mathrm{m}$ and $92 \mu \mathrm{m}$. While, homogenization speed of $4000 \mathrm{rpm}$ yield microspheres with the mean particle size of $51 \mu \mathrm{m}, 46 \mu \mathrm{m}, 38 \mu \mathrm{m}$ and $48 \mu \mathrm{m}$. Particle size reduction was achieved during manufacturing of microspheres by high-speed homogenization through rotor/stator generators with two teeth rows, each having tip speed of 10.0 to 31.0 $\mathrm{m} / \mathrm{s}$. Higher homogenization speed yield lower mean particle size. Larger the size of microspheres lower will be the surface area per unit volume and rate of encapsulated drug release is reduced [26]. Particle size distribution of prepared Paliperidone microspheres showed in fig. 2. 


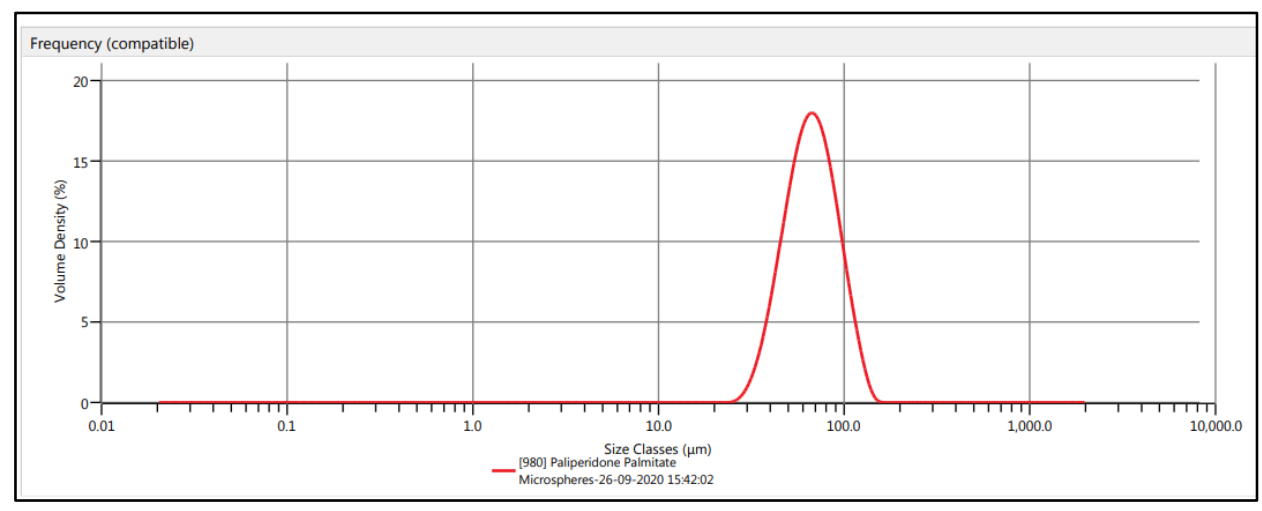

Fig. 2: Particle size distribution graph of paliperidone palmitate microspheres formulation

Table 3: Analysis of variance of calculated model

\begin{tabular}{|c|c|c|c|c|c|}
\hline Result of ANOVA & Mean particle size & Drug loading & Entrapment efficiency & Burst release & Drug release on day 21 \\
\hline \multicolumn{6}{|l|}{ Regression } \\
\hline Sum of squared & 4959.77 & 608.28 & 768.16 & 17.12 & 3473.30 \\
\hline Degree of freedom & 6 & 9 & 9 & 9 & 3 \\
\hline Mean squares & 826.63 & 67.59 & 85.35 & 1.90 & 1157.77 \\
\hline F-value & 66.54 & 303.44 & 62.73 & 26.12 & 22.37 \\
\hline $\mathrm{p}$ & $<0.0001$ & $<0.0001$ & $<0.0001$ & $<0.0001$ & $<0.0001$ \\
\hline \multicolumn{6}{|l|}{ Residual } \\
\hline Sum of squared & 124.22 & 1.56 & 9.52 & 0.5098 & 672.94 \\
\hline Degree of freedom & 10 & 7 & 7 & 7 & 13 \\
\hline Mean squares & 12.42 & 0.2227 & 1.36 & 0.0728 & 51.56 \\
\hline \multicolumn{6}{|l|}{ Lack of fit test } \\
\hline Sum of squared & 119.56 & 1.38 & 8.49 & 0.4969 & 658.94 \\
\hline Degree of freedom & 8 & 5 & 5 & 5 & 11 \\
\hline Mean squares & 14.94 & 0.2758 & 1.70 & 0.0994 & 59.90 \\
\hline F-value & 6.40 & 3.06 & 3.27 & 15.45 & 8.56 \\
\hline $\mathrm{p}$ & 0.1420 & 0.2641 & 0.2504 & 0.0619 & 0.1092 \\
\hline Correlation Coefficient $\left(\mathrm{R}^{2}\right)$ & 0.9756 & 0.9974 & 0.9878 & 0.9711 & 0.8377 \\
\hline Correlation of variation & 5.26 & 1.36 & 1.40 & 18.68 & 9.17 \\
\hline
\end{tabular}

Table 4: Regression analysis for responses $Y_{1}, Y_{2}, Y_{3}, Y_{4}$ and $Y_{5}$

\begin{tabular}{|c|c|c|c|c|c|c|}
\hline \multicolumn{2}{|c|}{ Models } & R-squared & Adjusted R-squared & Predicted R-squared & SD & Remarks \\
\hline \multicolumn{7}{|c|}{ Response (Y1) } \\
\hline 1. & Linear & 0.9416 & 0.9281 & 0.8816 & 4.78 & - \\
\hline 2. & $2 \mathrm{FI}$ & 0.9755 & 0.9609 & 0.9315 & 3.52 & Suggested \\
\hline 3. & Quadratic & 0.9803 & 0.9551 & 0.8726 & 3.77 & - \\
\hline \multicolumn{7}{|c|}{ Response (Y2) } \\
\hline 1. & Linear & 0.9597 & 0.9504 & 0.9239 & 1.37 & - \\
\hline 2. & 2FI & 0.9756 & 0.9609 & 0.9246 & 1.22 & - \\
\hline 3. & Quadratic & 0.9974 & 0.9941 & 0.9788 & 0.47 & Suggested \\
\hline \multicolumn{7}{|c|}{ Response (Y3) } \\
\hline 4. & Linear & 0.8676 & 0.8371 & 0.7759 & 2.81 & - \\
\hline 5. & $2 \mathrm{FI}$ & 0.8894 & 0.8230 & 0.6427 & 2.93 & - \\
\hline 6. & Quadratic & 0.9877 & 0.9720 & 0.8941 & 1.17 & Suggested \\
\hline \multicolumn{7}{|c|}{ Response (Y4) } \\
\hline 1. & Linear & 0.8723 & 0.8429 & 0.7512 & 0.41 & - \\
\hline 2. & $2 \mathrm{FI}$ & 0.9160 & 0.8657 & 0.5780 & 0.38 & - \\
\hline 3. & Quadratic & 0.9710 & 0.9339 & 0.8034 & 0.27 & Suggested \\
\hline \multicolumn{7}{|c|}{ Response (Y5) } \\
\hline 1. & Linear & 0.8376 & 0.8002 & 0.7015 & 7.19 & - \\
\hline 2. & $2 \mathrm{FI}$ & 0.8944 & 0.8311 & 0.6513 & 6.61 & - \\
\hline 3. & Quadratic & 0.9470 & 0.8790 & 0.5410 & 5.60 & Suggested \\
\hline
\end{tabular}

\section{Drug loading $\left(\mathrm{Y}_{2}\right)$}

The drug loading was found to be a function of the composition of microspheres i.e. drug: polymer ratio. Experimental runs were designed with drug: polymer ratio of $1: 1,1: 1.5$ and $1: 2$. Experiments were planned in such a way that theoretical drug loading should not exceed $50 \%$ drug load (i.e. 1:1 Drug: Polymer ratio). It is expected by virtue of stoichiometry that targeting drug loading above $50 \%$ may result in crystallization of some drug fraction, which may lead to higher burst release in vitro release profile. In vitro drug release profile with higher burst release is not desired characteristics of the long-acting injectable drug product.

ANOVA data in table 2 for response drug loading depicts that factor $\mathrm{X}_{1}$ (Drug: Polymer ratio), $\mathrm{X}_{2}$ (Homogenization speed) and $\mathrm{X}_{3}$ (rate of addition) are statistically significant main effects at level 0.05. Two- 
way interaction of $\mathrm{X}_{1}$ (Drug: Polymer ratio) and $\mathrm{X}_{2}$ (Homogenization speed) found significantly impacting drug loading at level 0.05 . The lack of fit F-value of 3.06 implies that the lack of fit is not significant relative to pure error. The predicted $\mathrm{R}^{2}$ of 0.9788 is in reasonable agreement with adjusted $\mathrm{R}^{2}$ of 0.9942 i.e. the difference is less than 0.2 . The signal-to-noise ratio of 64.426 indicates adequate signal. Regression analysis data for response drug loading showed in table 4 .

DOE model for Drug Loading (\%):
Drug Loading $(\%)=35.38+6.82 \mathrm{X}_{1}-2.81 \mathrm{X}_{2}-2.03 \mathrm{X}_{3}-1.09 \mathrm{X}_{1}{ }^{*} \mathrm{X}_{2}-$ $0.1375 \mathrm{X}^{*} * \mathrm{X}_{3}+0.0875 \mathrm{X}_{2} * \mathrm{X}_{3}$

Contour plot and three-dimensional surface plot of drug loading (\%) shows the impact of variation of factor values of on drug loading (fig. $3)$. The increase drug: polymer ratio $\left(X_{1}\right.$ found to decrease the drug loading of prepares microspheres. The increase in homogenization speed $\left(\mathrm{X}_{2}\right)$ and rate of addition $\left(\mathrm{X}_{3}\right)$ reduces the drug loading of microspheres (fig. 3).
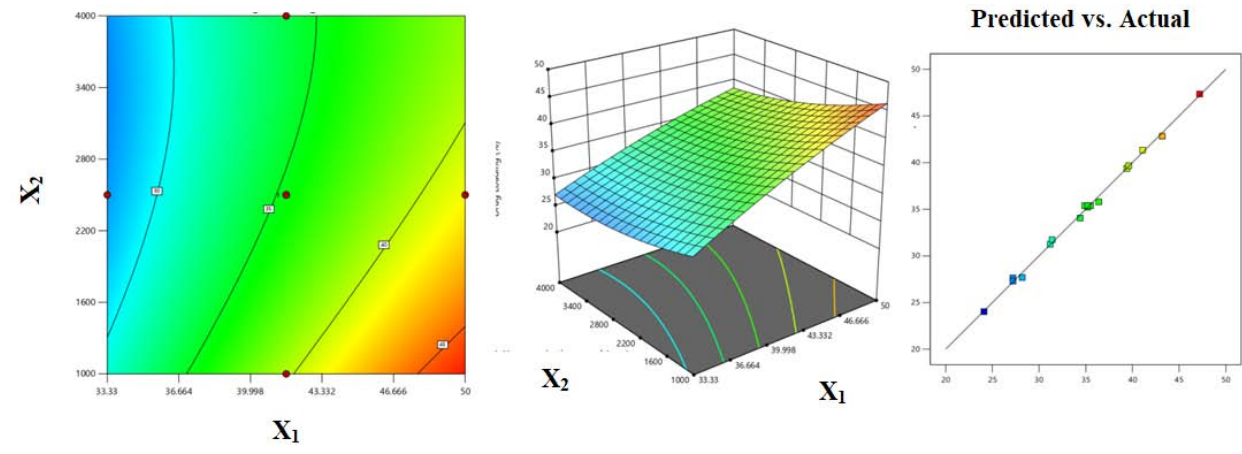

Drug Loading (\%)

Fig. 3: Graphical representation of data-drug loading $\left(Y_{2}\right)$

\section{Entrapment efficiency $\left(\mathrm{Y}_{3}\right)$}

Entrapment efficiency is a crucial parameter in the design of drug loaded PLGA microspheres. The obvious aim of dosage development is to entrap maximum drug in polymer matrix. Drug: polymer ratio was found to directly impacting the entrapment of drugs inside the PLGA matrix. As well, mechanical parameter such as homogenization speed (X2) was found to impact the entrapment efficiency of microspheres.

ANOVA data in table 3 of response entrapment efficiency depicts that $\mathrm{X}_{2}$ (Homogenization speed) and $\mathrm{X}_{3}$ (rate of addition) are statistically significant main effects at level 0.05. Two-way interaction of $\mathrm{X}_{1}$ (Drug: Polymer ratio) and $\mathrm{X}_{2}$ (Homogenization speed) found significantly impacting entrapment efficiency at level 0.05 . The lack of fit F-value of 3.27 implies that the lack of fit is not significant relative to the pure error. The predicted $R^{2}$ of 0.8941 is in reasonable agreement with an adjusted $R^{2}$ of 0.9720 i.e. the difference is less than 0.2 . The signal-to-noise ratio of 27.422 indicates adequate signal. Regression analysis data for response entrapment efficiency showed in table 4.

DOE model for Drug Loading (\%):

Drug Loading $(\%)=84.98-0.1541 \quad \mathrm{X}_{1}-6.54 \mathrm{X}_{2}-4.97 \mathrm{X}_{3}-$ $1.29 \mathrm{X}_{1} * \mathrm{X}_{2}+0.6128 \mathrm{X} 1 * \mathrm{X}_{3+} 0.2875 \mathrm{X}_{2} * \mathrm{X}_{3}$

Contour plot and three-dimensional surface plot of entrapment efficiency (\%) shows the impact of variation of factor values of on entrapment efficiency (fig.4). The increased drug: polymer ratio ( $\mathrm{X}_{1}$ found to decrease the entrapment efficiency of prepares microspheres. The increase in drug: polymer ration $\left(\mathrm{X}_{1}\right)$ and homogenization speed $\left(\mathrm{X}_{2}\right)$ reduces the entrapment efficiency of microspheres (fig. 4).
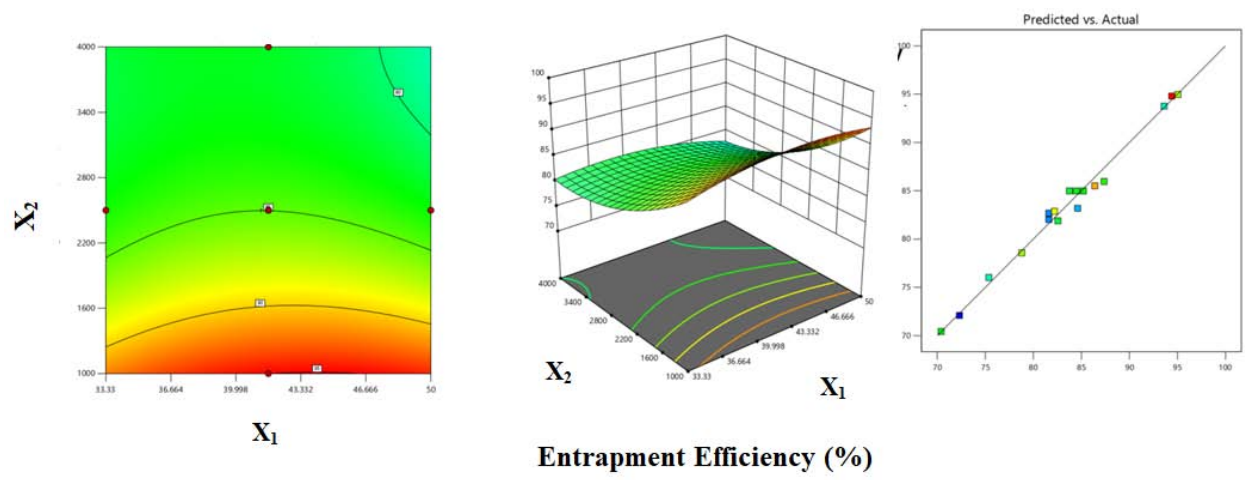

Fig. 4: Graphical representation of data-entrapment efficiency $\left(\mathrm{Y}_{3}\right)$

\section{Burst release $\left(Y_{4}\right)$ and drug release on day $60\left(Y_{5}\right)$}

Results of burst release testing at $24 \mathrm{~h}$ are represented in table 2 . Mostly burst release from polymeric microspheres is governed by surface distributed drugs on the microspheres. In these experiments, PLGA 75:25 was used to formulate all the experimental runs of the design. Lactide ratio is the liming factor for drug release from PLGA based systems. As all these experiments were carried out using similar lactide composition in microspheres, process parameters play crucial role in burst release and release profile over the period of time. Lactide component of PLGA polymer imparts inherent lipophilicity to polymeric system.

ANOVA data in table 3 of response burst release depicts that $\mathrm{X}_{1}$ (Drug: polymer ratio), $\mathrm{X}_{2}$ (Homogenization speed) and $\mathrm{X}_{3}$ (rate of addition) are statistically significant main effects at level 0.05 . Two 
way interaction of $\mathrm{X}_{1}$ (Drug: Polymer ratio) and $\mathrm{X}_{2}$ (Homogenization speed) found significantly impacting burst release at level 0.05 . The lack of fit F-value of 15.45 implies that the lack of fit is not significant relative to the pure error. The predicted $\mathrm{R}^{2}$ of 0.8034 is in reasonable agreement with an adjusted $R^{2}$ of 0.9339 i.e. the difference is less than 0.2 . The signal- to-noise ratio of 17.790 indicates an adequate signal. Regression analysis data for response burst release showed in table 4 .

DOE model for Burst release (\%):

Burst release $(\%)=-10.17+0.4867 \mathrm{X}_{1}+0.000278 \mathrm{X}_{2}+0.264 \mathrm{X}_{3} 1.00 \mathrm{X}_{4}$ $0.000006 \mathrm{X}_{1} * \mathrm{X}_{2}-0.01361 \mathrm{X}_{1} * \mathrm{X}_{3}-0.0400 \mathrm{X}_{1} * \mathrm{X}_{4}$
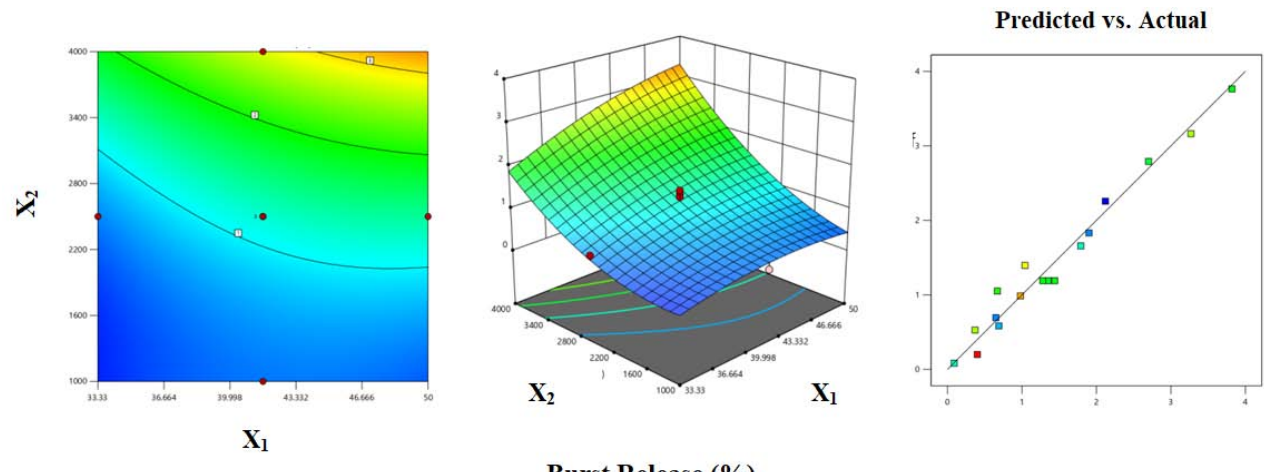

Burst Release (\%)

Fig. 4: Graphical representation of data-burst release $\left(\mathrm{Y}_{4}\right)$

Contour plot and three-dimensional surface plot of burst release vs. drug: polymer ratio, rate of addition (fig. 4) shows that decrease in drug: polymer ratio and rate of addition decreases the burst release of resultant microspheres. Results of burst release of experimental run 1 to 17 showed that burst release was observed higher in high drug-loaded microspheres. Therefore, higher drug loading may not always be advantageous to get desired drug release profile. In the contrary, the lower mean particle size of microspheres increases the exposed surface area of microspheres and increases the burst release of drug from microspheres. It is important to achieve the optimum mean particle size and optimum drug loading to get a drug release profile suitable for long-acting injectable formulations. It can be achieved by properly optimizing various process parameters during the development of long-acting injectable microspheres. In these experimental trials, lower burst release was obtained with run
1,8 and 15. Presence of fine fraction in population contributes more towards burst release.

ANOVA data in table 3 for response drug release on day 60 depicts that $X_{1}$ (Drug: polymer ratio), $X_{2}$ (Homogenization speed) and $X_{3}$ (rate of addition) are statistically significant main effects at level 0.05. No two-way interaction of inputs factors was found to significantly impacting drug release on day 60 . The lack of fit F-value of 8.56 implies that the lack of fit is not significant relative to pure error. The predicted $\mathrm{R}^{2}$ of 0.7015 is in reasonable agreement with adjusted $\mathrm{R}^{2}$ of 0.8002 i.e. the difference is less than 0.2 . The signalto-noise ratio of 17.708 indicates an adequate signal. Regression analysis data for response burst release showed in table 4.

DOE model for drug release (\%):

Drug release on day $60(\%)=78.47+8.20 \mathrm{X}_{1}+14.70 \mathrm{X}_{2}+8.00 \mathrm{X}_{3}$
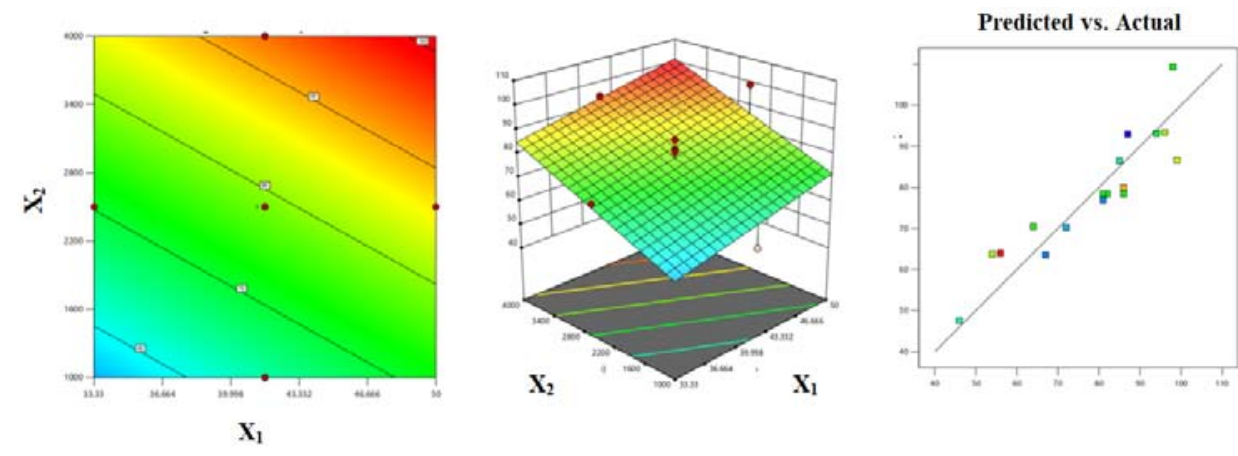

Drug release on day $60(\%)$

Fig. 5: Graphical representation of data-drug release on day $60\left(Y_{5}\right)$

Contour plot of drug release on day 60 vs. drug: polymer ratio, homogenization speed (fig. 5) shows that drug: polymer ratio and homogenization speed increases drug release on day 60 of resultant microspheres increases. Release from polymeric microspheres occurs due to diffusion and/or homogeneous bulk erosion of the biopolymer. Release rate impacted by physico-chemical parameters of encapsulated drug. Hydrophobicity, size of molecule, partition coefficient, and charge has greater influence on drug release of encapsulated drug from polymer matrix [27. 28]. Water uptake in the polymer matrix leads to hydrolysis of polymer. Monomers and oligomers diffuse out of polymer matrix through pores resulting in drug erosion from polymer matrix.

\section{Morphology}

Surface morphology of microspheres was studied by SEM technique revealed that shape of prepared microspheres was found spherical with smooth surface as shown in fig. 6. No broken microspheres were observed in SEM analysis. Smooth surface of microspheres is important to get good flow properties of microspheres and have industrial importance during filling of microspheres in vials. SEM of all the formulation showed spherical shape of prepared. Particle shape was studied under different magnifications. Overall, the process technology and parameters were found capable to produce spherical shape of microspheres consistently in all the runs. 


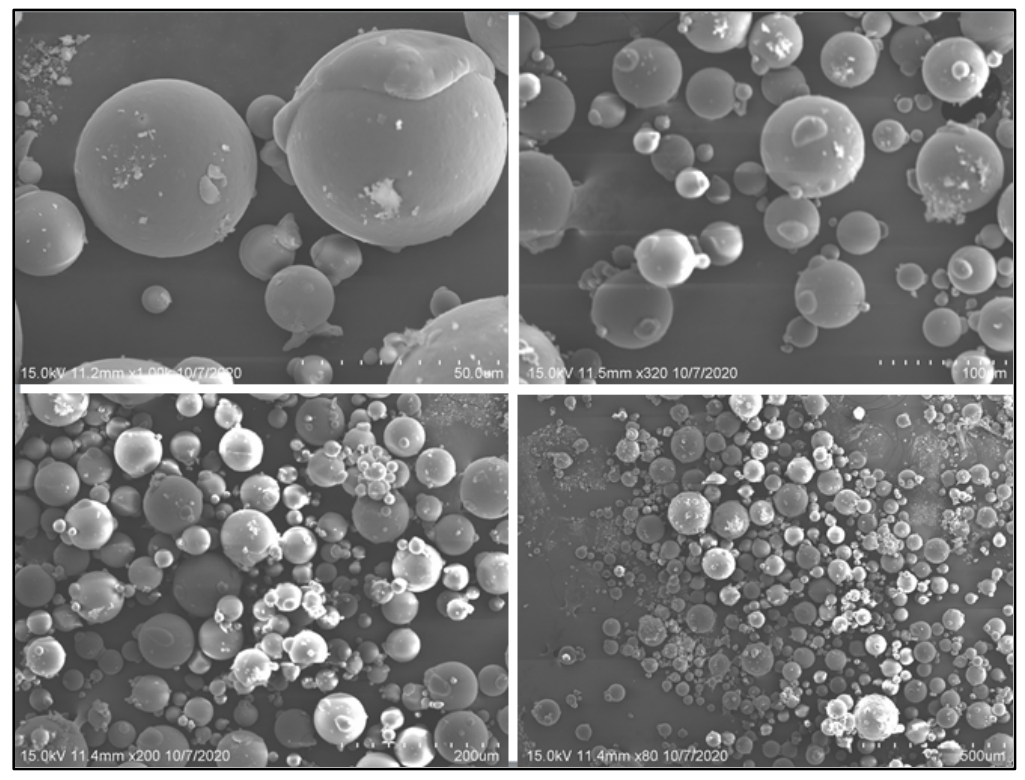

Fig. 6: SEM images-paliperidone microspheres

\section{DSC}

DSC analysis was carried out for Paliperidone palmitate, PLGA 75:25, Placebo and Paliperidone microspheres. DSC thermograms are shown in fig. 7. Paliperidone palmitate and microspheres has shown characteristic endothermic peak at $119.72{ }^{\circ} \mathrm{C}$ and $119.83{ }^{\circ} \mathrm{C}$ respectively. Thermograms confirm the crystalline nature of paliperidone. The peak intensity of drug has been reduced in formulated microspheres while the melting point remains unchanged. The thermograms of PLGA 75:25 shown glass transition temperature at $59.44{ }^{\circ} \mathrm{C}$. Glass transition temperature for placebo, physical mixture and formulated microspheres was found to be $59.66^{\circ} \mathrm{C}, 59.91{ }^{\circ} \mathrm{C}$ and $58.96^{\circ} \mathrm{C}$ respectively. Above glass transition temperature, mobility of polymer chain increases and polymer transitions from hard, glassy material to soft rubbery form. PLGA polymers are meant for use below its glass transition temperatures. Above glass transition temperature, PLGA polymers are known to alter release modifying characteristics of drug systems. Prepared Paliperidone microspheres are intended to intramuscular administration. Intramuscular site has a temperature of around 37 ${ }^{\circ} \mathrm{C}$. Formulated microspheres were found suitable for the intended route of administration i.e. intra-muscular.

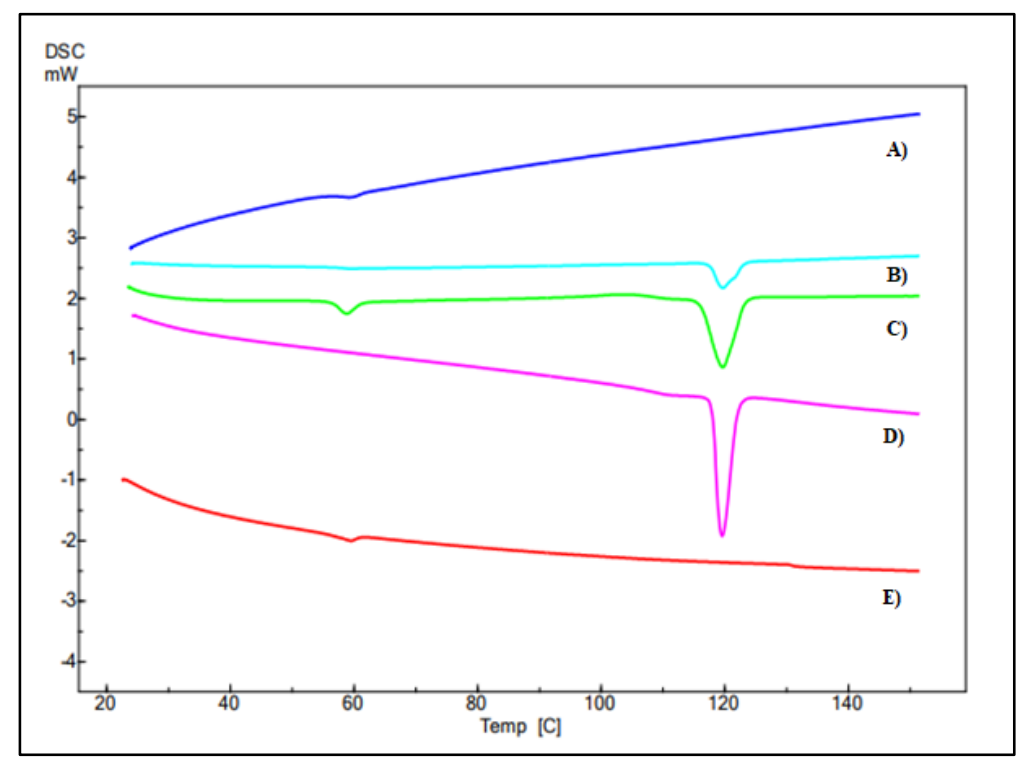

Fig. 7: DSC Thermogram of (A) PLGA 75:25,(B) Physical mixture,(C) Paliperidone palmitate microspheres, (D) Paliperidone palmitate API, (E) Placebo

\section{FT-IR}

Fig. 8 shows FT-IR of Paliperidone palmitate, PLGA 75:25, physical mixture, placebo and formulated paliperidone microspheres. PLGA 75:25 showed the typical IR peaks, $\mathrm{H}$-bonded $\mathrm{O}-\mathrm{H}$ stretch at 3448 $\mathrm{cm}^{-1}, \mathrm{C}-\mathrm{H}$ asymmetric stretch at $2924 \mathrm{~cm}^{-1}$ and C-H symmetric stretch at $2852 \mathrm{~cm}^{-1}, \mathrm{C}=0$ stretch of $1745 \mathrm{~cm}^{-1}, \mathrm{C}-0$ stretch of $1051 \mathrm{~cm}^{-1}$. FTIR spectra of Paliperidone palmitate showed typical peaks, $\mathrm{O}-\mathrm{H}$ stretch at $3446 \mathrm{~cm}^{-1}, \mathrm{C}-\mathrm{H}$ stretch at $2920 \mathrm{~cm}^{-1}$ and $2850 \mathrm{~cm}^{-1}, \mathrm{C}=0$ stretch at $1737 \mathrm{~cm}^{-1}, \mathrm{C}=\mathrm{N}$ stretch at $1649 \mathrm{~cm}^{-1}, \mathrm{C}=\mathrm{C}$ stretch at 1529 $\mathrm{cm}^{-1}$, and C-F stretch at $1122 \mathrm{~cm}^{-1}, \mathrm{C}-\mathrm{H}$ deformation vibration at 837 $\mathrm{cm}^{-1}$. Formulated Paliperidone palmitate microspheres showed FTIR 
peaks at $\mathrm{O}-\mathrm{H}$ stretch at $3448 \mathrm{~cm}^{-1}, \mathrm{C}-\mathrm{H}$ asymmetric stretch at 2922 $\mathrm{cm}^{-1}$ and symmetric stretch at $2850 \mathrm{~cm}^{-1}, \mathrm{C}=0$ stretch at $1755 \mathrm{~cm}^{-1}$, $\mathrm{C}=\mathrm{N}$ stretch at $1656 \mathrm{~cm}^{-1}, \mathrm{C}=\mathrm{C}$ stretch at $1546 \mathrm{~cm}^{-1}$, and $\mathrm{C}-\mathrm{F}$ stretch at $1124 \mathrm{~cm}^{-1}, \mathrm{C}-\mathrm{H}$ deformation vibration at $837 \mathrm{~cm}^{-1}$. Only shift was observed from $1737 \mathrm{~cm}^{-1}$ to $1755 \mathrm{~cm}^{-1}$ may be due to hydrogen bonding. Broadening of $\mathrm{C}-\mathrm{H}$ stretch from API to microspheres accounted to the additive contribution of $\mathrm{C}-\mathrm{H}$ from API and PLGA 75:25. No other significant shifts or interactions were observed.

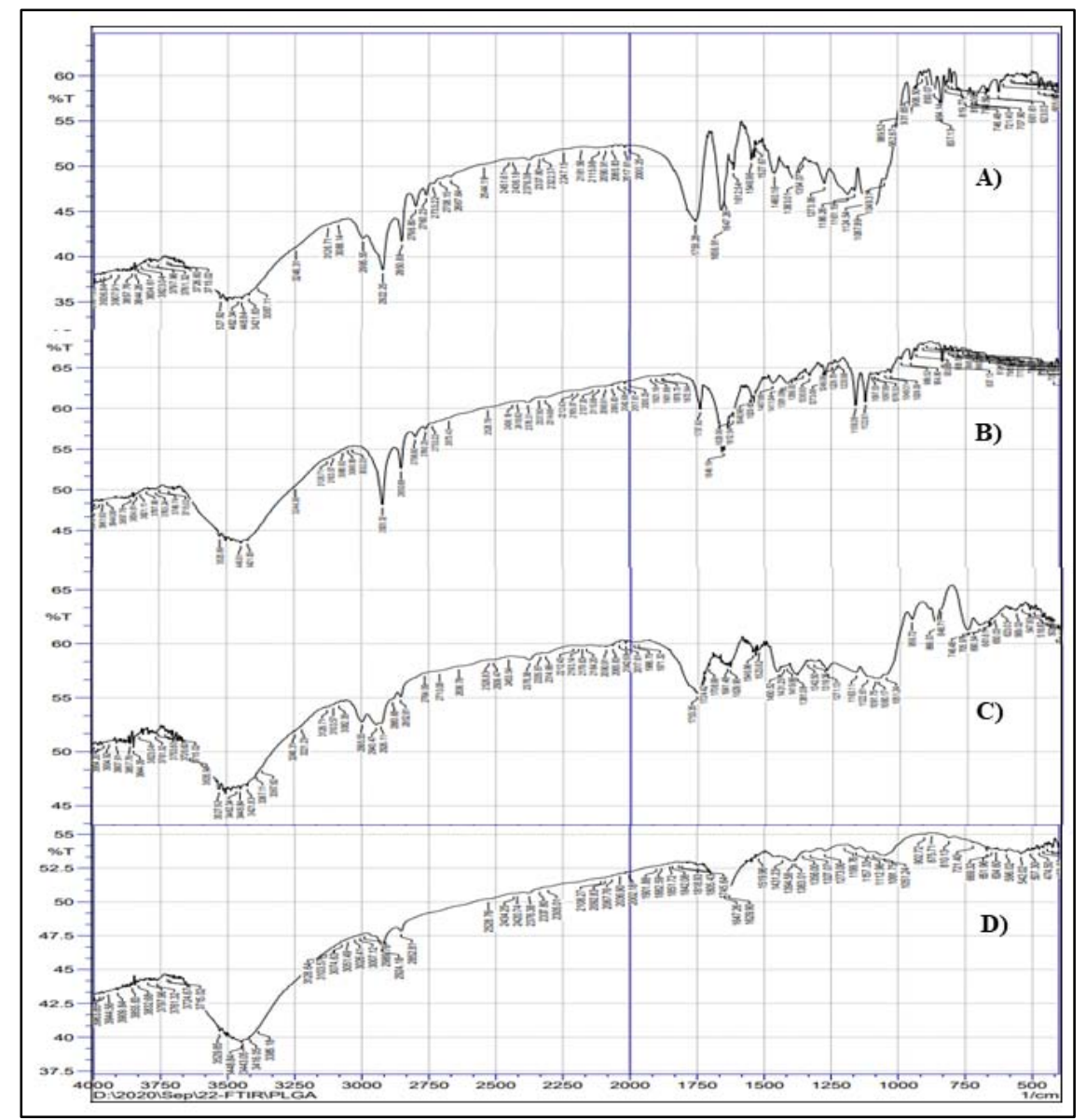

Fig. 8: FTIR Spectra of (A) Paliperidone palmitate microspheres, (B) Paliperidone palmitate API, (C) Placebo, (D) PLGA 75:25

\section{Lactide: glycolide ratio}

${ }^{1} \mathrm{H}$ NMR spectroscopy technique was used for determination of lactic acid to glycolic acid ratio of PLGA polymer and microsphere formulation. Deuterated chloroform was used as a solvent for NMR testing. LA: GA ratio was analysed for PLGA and optimized microsphere formulation to check compatibility with excipients and solvents used and to study any impact of processing parameters during microspheres manufacturing. Fig. 9 (A, B, C), for PLGA, peak integration at $52 \mathrm{ppm}$ and $4.8 \mathrm{ppm}$ are 1.85 and 1.20 , respectively. For Paliperidone palmitate microspheres, peak integration at 52 ppm and 4.8 ppm are 10.75 and 7.10, respectively. LA: GA ratio for PLGA and paliperidone microsphere was found to be 75.5: 24.5 and 75.2: 24.8 respectively. Based on values of LA: GA ratio of PLGA and prepared microspheres, it can be concluded that LA: GA ratio was remained unaltered in microsphere formulation.

\section{End cap analysis}

${ }^{13}$ CNMR spectroscopy technique was used for end group analysis of PLGA polymer and microsphere formulation. Peak assignments are shown in fig. 10 (A, B). Peaks at 16 ppm, 20 to 30 ppm, 50 to 80 ppm and 160 to $180 \mathrm{ppm}$ are ascribed to carbon. Peaks at $16 \mathrm{ppm}$ and in between 160 to $180 \mathrm{ppm}$ indicate the presence of ester carbons in ${ }^{13} \mathrm{C}$ NMR spectra. Based on ${ }^{13} \mathrm{C}$ NMR spectra of PLGA and prepared microspheres, it can be concluded that end group characteristics were remained unaltered in microsphere formulation.

\section{Selection of optimum conditions}

The optimum conditions for manufacturing of PP microspheres were obtained using software numerical and graphical optimization using Design Expert ${ }^{\circledR}$ software, version 12.0 [29]. The desirability function scale operates between 0 and 1 . Desirability value of 1 represents a fully desired response. The desirability for each response was achieved by setting the goals in ranges [30]. To get microspheres with optimum characteristics, goals for dependent variables were fixed as 50 to $100 \mu \mathrm{m}$ (for mean particle size), 24.1 to $47.2 \%$ (for drug loading), 70.4 to $95.04 \%$ (Entrapment efficiency), 0.09 to $2.5 \%$ (for burst release) and 80 to $90 \%$ (for drug release on day 21). After treatment of responses of all seventeen formulations, the software has provided one hundred solutions having combinations of independent variables to achieve desirability function of 1 . Fig. 11 represents overlay plot obtained graphical optimization respectively. Overlay plot was used to visually identify an area where the predicted means of one or more response variables are in an acceptable range for successful manufacturing of PP microspheres.

\section{Verification of predictive model}

The verification of model equation for prediction of responses was performed by manufacturing batches using software suggested solution at the levels of the drug: polymer ratio $(45.15 \%, 35.41 \%$, and $38.52 \%$ ), homogenization speed (2460 rpm, $3925 \mathrm{rpm}$, and $3277 \mathrm{rpm}$ ) and rate of addition (11.96 $\mathrm{ml} / \mathrm{min}, 6.46 \mathrm{ml} / \mathrm{min}$, and $15.19 \mathrm{ml} / \mathrm{min})$. These conditions were considered to be optimum by the RSM optimization approach. After manufacturing of PP microspheres, the experimental results vs. predicted values were compared. The results were presented in table 5 . 


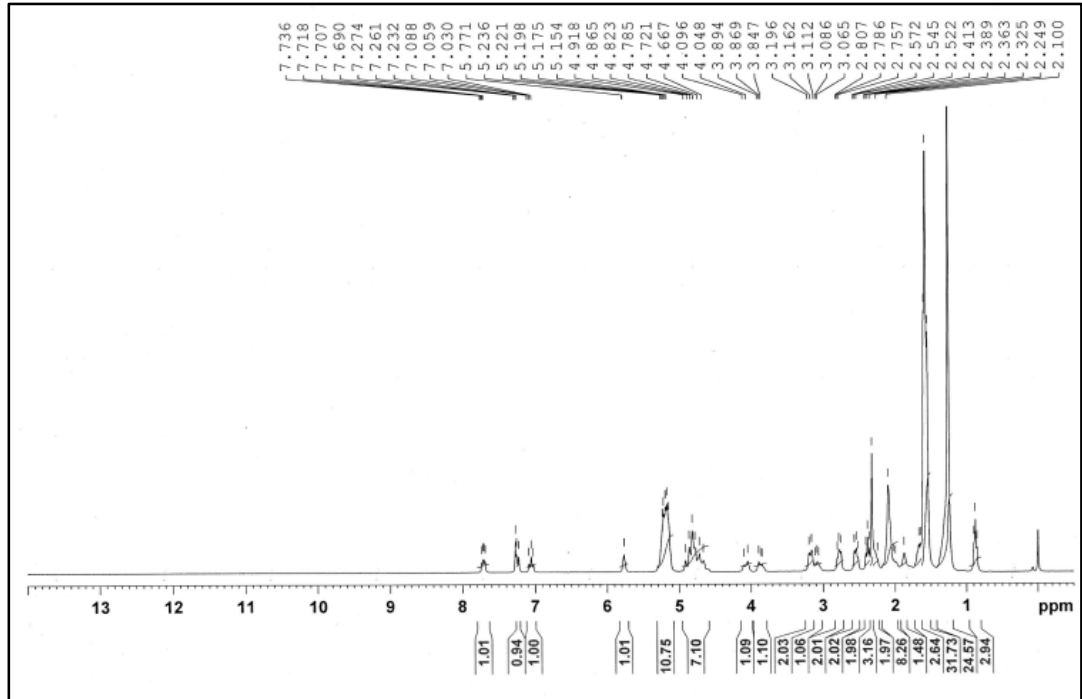

A.

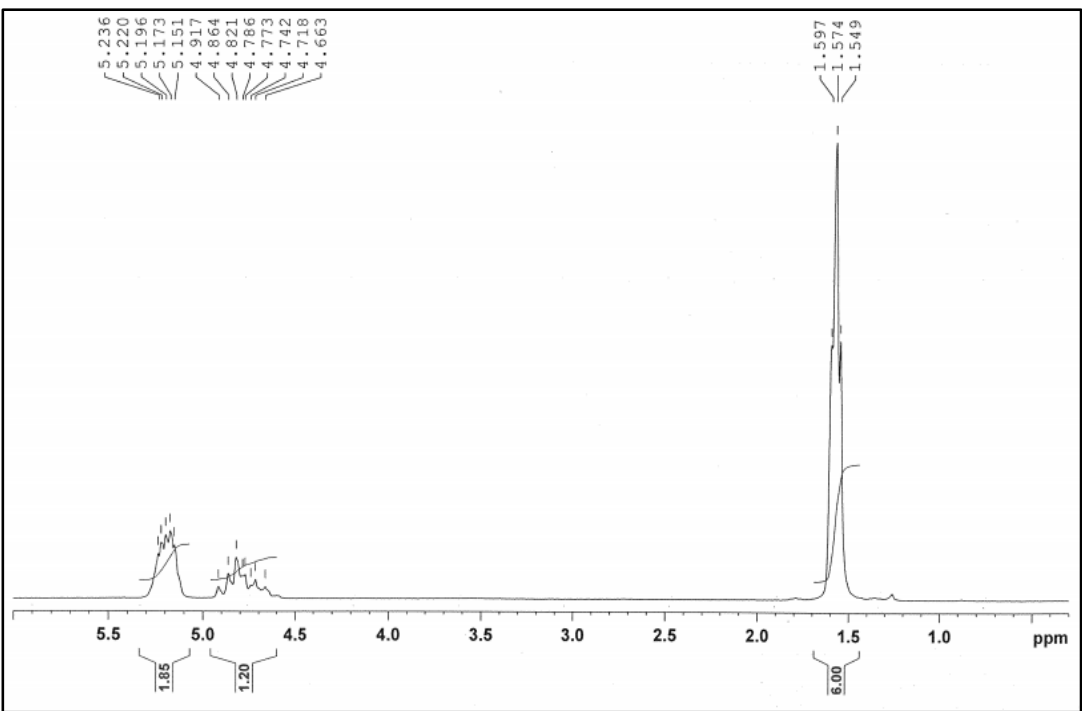

B.

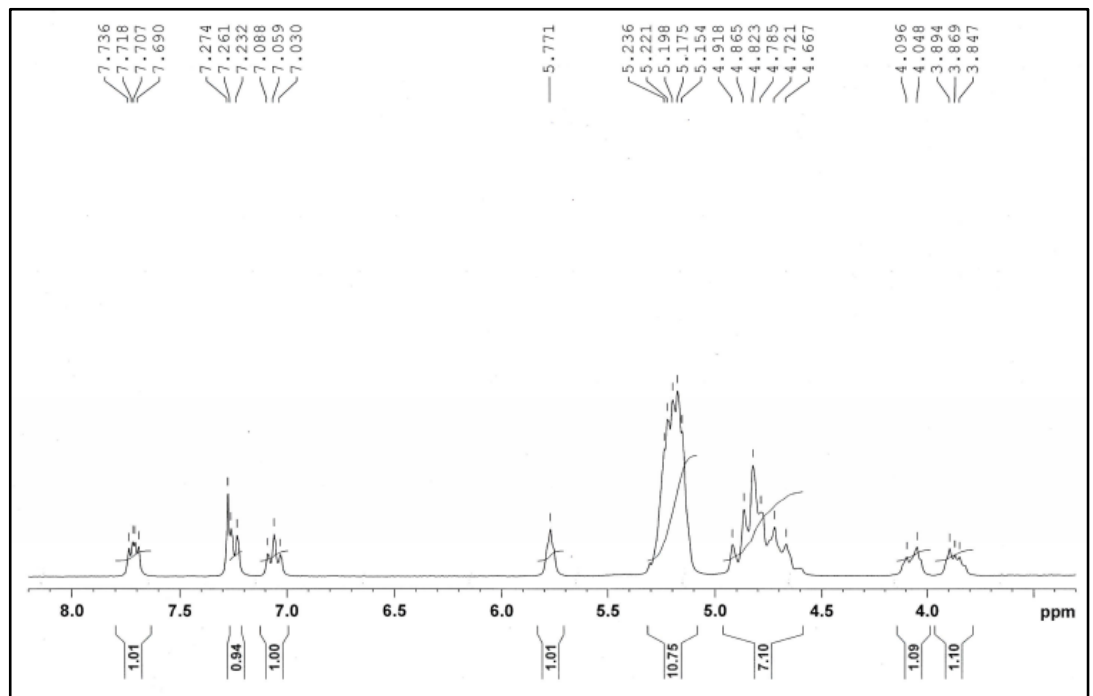

C.

Fig. 9: ${ }^{1} \mathrm{H}$ NMR spectra of (A) PLGA 75:25, (B) Paliperidone palmitate microspheres, (C) Paliperidone palmitate microspheres (Zoomed spectra) 


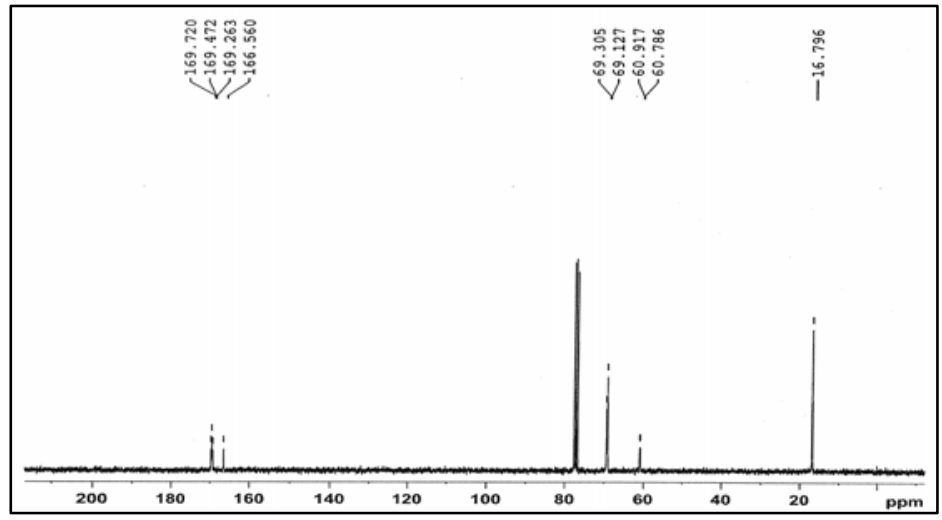

A.

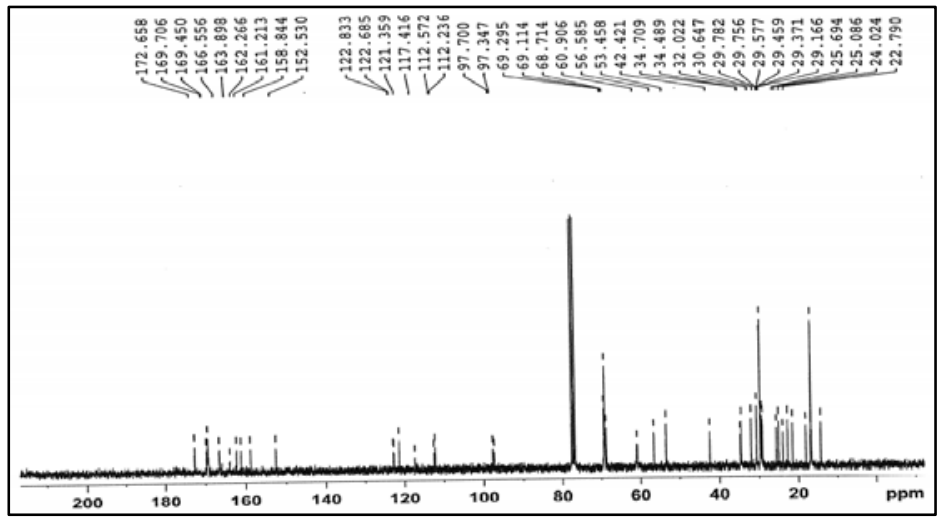

B.

Fig. 10: ${ }^{13}$ C NMR spectra of (A) PLGA 75:25 (B) Paliperidone palmitate microspheres

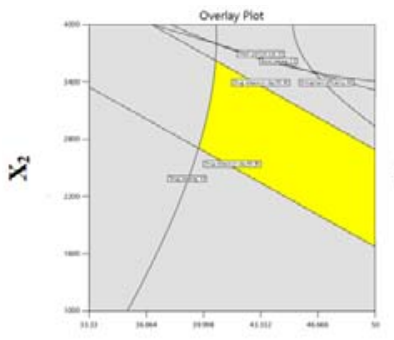

$\mathbf{X}_{1}$

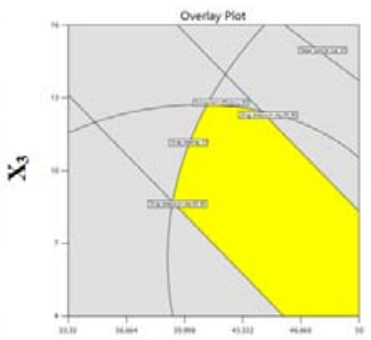

$\mathbf{X}_{1}$

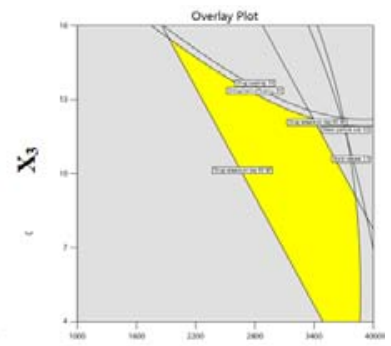

$\mathbf{X}_{2}$

Fig. 11: Overlay plots-X1 (Drug: polymer ratio), X2 (Homogenization speed) and X3 (rate of addition)

Table 5: Composition of checkpoint formulations with predicted and observed values of responses

\begin{tabular}{|c|c|c|c|c|c|c|c|}
\hline \multirow[t]{2}{*}{ Formulation } & \multicolumn{3}{|c|}{ Formulation components } & \multirow{2}{*}{$\begin{array}{l}\text { Response } \\
\text { variable }\end{array}$} & \multirow{2}{*}{$\begin{array}{l}\text { Observed } \\
\text { values }\end{array}$} & \multirow{2}{*}{$\begin{array}{l}\text { Predicated } \\
\text { values }\end{array}$} & \multirow{2}{*}{$\begin{array}{l}\text { Percentage of } \\
\text { error }\end{array}$} \\
\hline & $\mathbf{X}_{1}$ & $\mathbf{X}_{2}$ & $\mathbf{X}_{3}$ & & & & \\
\hline \multirow[t]{5}{*}{ CPF-1 } & 45.15 & 2460 & 11.96 & $\mathrm{Y}_{1}$ & 61.04 & 62.40 & 2.23 \\
\hline & & & & $\mathrm{Y}_{2}$ & 35.98 & 37.31 & 3.70 \\
\hline & & & & $\mathrm{Y}_{3}$ & 80.63 & 82.79 & 2.68 \\
\hline & & & & $\mathrm{Y}_{4}$ & 1.37 & 1.41 & 2.92 \\
\hline & & & & $\mathrm{Y}_{5}$ & 86.42 & 84.12 & 2.66 \\
\hline \multirow[t]{5}{*}{ CPF-2 } & 35.41 & 3925 & 5.50 & $\mathrm{Y}_{1}$ & 58.44 & 56.28 & 3.70 \\
\hline & & & & $\mathrm{Y}_{2}$ & 28.45 & 29.69 & 4.36 \\
\hline & & & & $\mathrm{Y}_{3}$ & 82.41 & 83.43 & 1.24 \\
\hline & & & & $\mathrm{Y}_{4}$ & 1.99 & 1.97 & 1.01 \\
\hline & & & & $\mathrm{Y}_{5}$ & 81.78 & 80.28 & 1.83 \\
\hline \multirow[t]{5}{*}{ CPF-3 } & 38.52 & 3277 & 13.78 & $\mathrm{Y}_{1}$ & 53.18 & 54.91 & 3.25 \\
\hline & & & & $\mathrm{Y}_{2}$ & 28.86 & 29.97 & 3.85 \\
\hline & & & & $\mathrm{Y}_{3}$ & 78.43 & 77.78 & 0.83 \\
\hline & & & & $\mathrm{Y}_{4}$ & 1.84 & 1.89 & 2.72 \\
\hline & & & & $Y_{5}$ & 86.42 & 88.03 & 1.86 \\
\hline
\end{tabular}

CPF: Check point formulation 


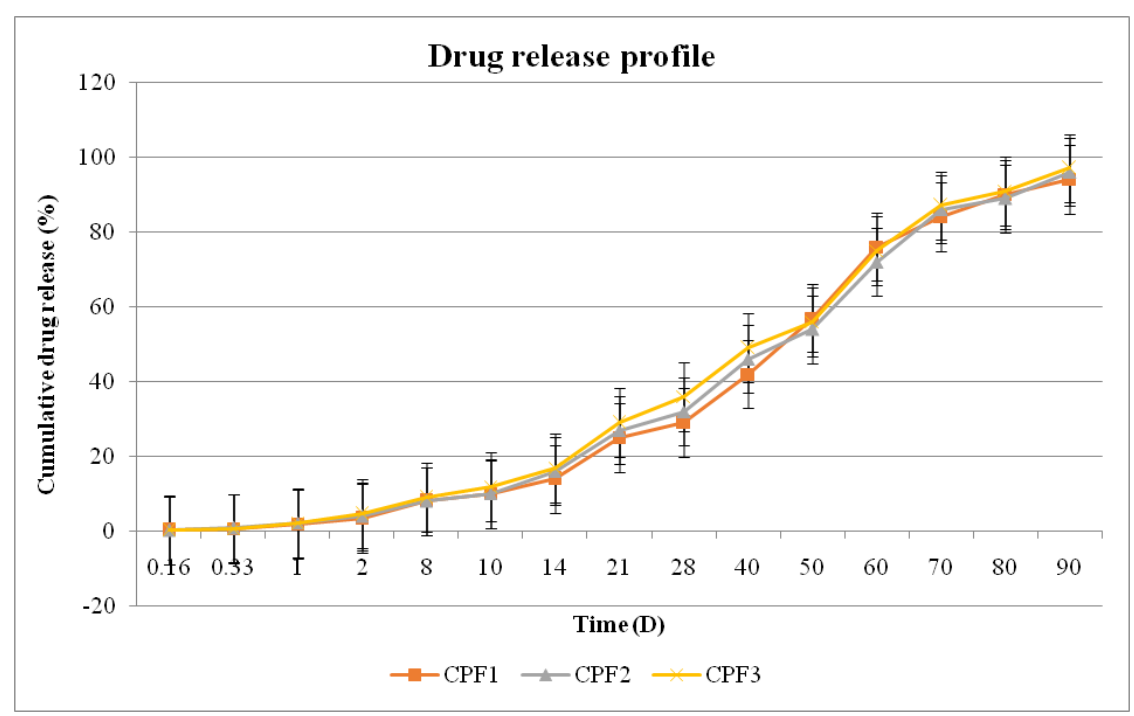

Fig. 12: Cumulative drug release from CPF-1, CPF-2 and CPF-3, sample size (n) =3

The observed values for mean particle size of CPF-1, CPF-2 and CPF-3 were found to be $61.04 \mu \mathrm{m}, 58.44 \mu \mathrm{m}, 53.18 \mu \mathrm{m}$ against predicted values of $62.40 \mu \mathrm{m}, 56.28 \mu \mathrm{m}$ and $54.91 \mu \mathrm{m}$, respectively. Drug release from sample CPF-1, CPF-2 and CPF-3 was studied. All three check point formulations showed a consistent drug release profile from microspheres. Drug release from PLGA based microspheres mainly governed by diffusion and/or erosion. The cumulative in vitro drug release profile of PP from microspheres showed in fig. 12. It showed that burst release from prepared microspheres was minimal. Burst release was followed by lag phase and constant release phase.

Table 6: Release kinetics and transport mechanism of checkpoint formulations

\begin{tabular}{llll}
\hline Model & Equation & Formulation code & \\
\cline { 2 - 3 } & & CPF-1 & CPF-2 \\
\hline Zero order & $\mathrm{m}_{0}-\mathrm{m}=\mathrm{kt}$ & 0.9865 & 0.9837 \\
First order & $\mathrm{In} \mathrm{m}=\mathrm{kt}$ & 0.9790 & 0.5108 \\
Higuchi's Model & $\mathrm{m}_{0}-\mathrm{m}=\mathrm{kt}^{1 / 2}$ & 0.5091 & 0.9495 \\
Korsmeyer peppas & $\mathrm{Log}\left(\mathrm{m}_{0}-\mathrm{m}\right)=\log \mathrm{k}+\mathrm{n} \log \mathrm{t}$ & 0.9573 & 0.9658 \\
Hixon Crowel & $\mathrm{mt}^{1 / 3}=\mathrm{m}_{0}^{1 / 3}-\mathrm{Kt}$ & 0.6965 & 0.4708 \\
\hline
\end{tabular}

$\mathrm{m}_{\mathrm{o}}$ is the initial drug amount; $\mathrm{m}$ is the amount of drug remaining at a specific time; $\mathrm{k}$ is the rate constant; $\mathrm{t}$ is the time; $\mathrm{r}^{2}$ is correlation coefficient; $\mathrm{n}$ is diffusion coefficient

Mathematical modelling of drug release of CPF-1, CPF-2 and CPF-3 showed near zero-order drug release from prepared $P P$ microspheres. The observed values of all responses were compared with predicted values and shown in table 5 . The percentage error in observed values and predicted values were found to be less than 5 $\%$. The samples of CPF-1, CPF- 2 and CPF-3 showed spherical shape and smooth surface. The data of verification of model revealed that developed models were well suited for the manufacturing of PP microspheres.

\section{CONCLUSION}

In the presented experimental work, PLGA based biodegradable microspheres formulation of PP was optimized using face centred central composite design (FC-CCD) using desirability function. The developed model was confirmed as definitive for deriving optimal independent variable values and successfully predicting responses for the manufacturing of PP microspheres. The responses obtained from seventeen formulation runs were showed strong effect of independent process variables on formation of PP microspheres. The observed responses of checkpoint formulations were found to be in close agreement with predicted values. The PP microspheres showed predominant zero-order drug release kinetics. The prepared microspheres were found to be spherical in shape and smooth in surface. DSC and FTIR studies showed that the ingredients used in formulations were compatible. LA: GA ratio of prepared microspheres was determined to be $75: 25$ using ${ }^{1} \mathrm{H}-\mathrm{NMR} .{ }^{13} \mathrm{C}$ NMR studies confirmed ester end cap of prepared PP microspheres. Therefore, it can be concluded that a three-factor, three-level Box-
Behnken design can be successfully used for the optimization of PP microspheres using emulsion solvent evaporation technique with minimum number of experimental runs.

\section{FUNDING}

Nil

\section{AUTHORS CONTRIBUTIONS}

All authors have contributed equally.

\section{CONFLICT OF INTERESTS}

\section{Declared none}

\section{REFERENCES}

1. Saundersa EC, Mooreb SK, Walshb O, Metcalfb SA, Budneyb AJ, Schererb E, et al. Perceptions and preferences for long-acting injectable and implantable medications in comparison to shortacting medications for opioid use disorders. J Subst Abuse Treat 2020;111:54-66.

2. Lin CH, Chen FC, Chan HU, Hsu CC. A comparison of long-acting injectable antipsychotics with oral antipsychotics on time to rehospitalization within $1 \mathrm{y}$ of discharge in elderly patients with schizophrenia. Am J Geriatric Psychiatry 2020;28:23-30.

3. Wei XL, Han YR, Quan LH, Liu CY, Liao YH. Oily nanosuspension for long-acting intramuscular delivery of curcumin didecanoate prodrug: preparation, characterization and in vivo evaluation. Eur J Pharm Sci 2013;49:286-93. 
4. Kohli S, Pal A, Jain S. Preparation, characterization and evaluation of poly(Lactide-co-glycolide) microspheres for the controlled release of zidovudine. Int J Pharm Pharm Sci 2017;9:70-7.

5. Kar K, Pal RN, Bala NN. Preparation, characterization and evaluation of ropinirole hydrochloride loaded controlled release microspheres using solvent evaporation technique. Int J Pharm Pharm Sci 2018;10:57-67.

6. Nanaki S, Barmpalexis P, Papakonstantinou Z, Christodoulou E, Kostoglou M, Bikiaris DN. Preparation of new risperidone depot microspheres based on novel biocompatible poly (Alkylene Adipate) polyesters as long-acting injectable formulations. J Pharm Sci 2018;107:2891-901.

7. Mei L, Xie Y, Wang B, Chen J, Quan G, Pan X, et al. Injectable in situ forming gel based on lyotropic liquid crystal for persistent postoperative analgesia. Acta Biomater 2018;67:99-110.

8. Kamali H, Khodaverdi E, Hadizadeh F, Yazdian Robati R, Haghbin A, Zohuri G. An in-situ forming implant formulation of naltrexone with minimum initial burst release using a mixture of PLGA copolymers and ethyl heptanoate as an additive: In vitro, ex-vivo, and in vivo release evaluation. J Drug Delivery Sci Technol 2018;47:95-105.

9. He M, Yang G, Zhao X, Zhang S, Gao Y. Intradermal implantable PLGA microneedles for etonogestrel sustained release. J Pharm Sci 2010;109:1958-66.

10. Liua G, Zhanga D, Yang Jb, Guoa H, Zhenga D, Jia L, et al. In vitro and in vivo evaluation of riccardin $\mathrm{D}$ nanosuspensions with different particle size. Colloids Surf B 2013;102:620-6.

11. Fond G, Korchia T, Sunhary PL, Godin O, Schurhoff F, Berna F, et al. Major depression, sleep, hostility and body mass index are associated with impaired quality of life in schizophrenia. Results from the FACE-SZ cohort. J Affect Disord 2020;274:617-23.

12. Moller HJ. Antipsychotic agents. Gradually improving treatment from the traditional oral neuroleptics to the first atypical depot. Eur Psychiatry 2005;20:379-85.

13. Bloch Y, Mendlovic S, Strupinsky S, Altshuler A, Fennig S, Ratzoni G. Injections of depot antipsychotic medications in patients suffering from schizophrenia: do they hurt? J Clin Psychiatry 2001;62:855-9.

14. Csernansky JG, Mahmoud R, Bremer R. A comparison of risperidone and haloperidol for the prevention of relapse in patients with schizophrenia. N Engl J Med 2002;346:16-22.

15. Rubio JM, Schoretsanitis G, John M, Tiihonen J, Taipale H, Guinart D, et al. Psychosis relapse during treatment with longacting injectable antipsychotics in individuals with schizophrenia-spectrum disorders: an individual participant data meta-analysis. Lancet Psychiatry 2020;7:749-61.
16. Correll CU, Rubio JM, Kane JM. What is the risk-benefit ratio of long-term antipsychotic treatment in people with schizophrenia? World Psychiatry 2018;17:149-60.

17. Makadia HK, Siegel SJ. Poly lactic-co-glycolic acid (PLGA) as biodegradable controlled drug delivery carrier. Polymers (Basel) 2011;3:1377-97.

18. Kapoor DN, Bhatia A, Kaur R, Sharma R, Kaur G, Dhawan S. PLGA: a unique polymer for drug delivery. Ther Delivery 2015;6:41-58.

19. Anderson JM, Shive MS. Biodegradation and biocompatibility of PLA and PLGA microspheres. Adv Drug Delivery Rev 1997;28:5-24

20. Nussbaum AM, Stroup TS. Oral paliperidone for schizophrenia. Cochrane Database Syst Rev 2012;3:12-8.

21. Zacher JL. Paliperidone extended-release tablets (Invega). Psychopharmacol Rev 2007;42:51-8.

22. Freitas S, Merkle H, Gander B. Microencapsulation by solvent extraction/evaporation: reviewing the state of the art of microsphere preparation process technology. J Controlled Release 2005;102:313-32.

23. Garner J, Skidmore S, Park H, Park K, Choi S, Wang Y. Beyond Q1/Q2: the impact of manufacturing conditions and test methods on drug release from plga-based microparticle depot formulations. J Pharm Sci 2018;107:353-61.

24. Fang Y, Zhang N, Li Q, Chen J, Xiong S, Pan W. Characterizing the release mechanism of donepezil-loaded PLGA microspheres in vitro and in vivo. 2019;51:430-7.

25. Garner J, Skidmore S, Park H, Park K, Choi S, Wang Y. A protocol for assay of poly(lactide-co-glycolide) in clinical products. Int J Pharm 2015;495:87-92.

26. Dawes GJS, Fratila-Apachitei LE, Mulia K, Apachitei I, Witkamp GJ, Duszczyk J. Size effect of PLGA spheres on drug loading efficiency and release profiles. J Mater Sci Mater M 2009;20:1089-94.

27. Siegel SJ, Kahn JB, Metzger K, Winey KI, Werner K, Dan N. Effect of drug type on the degradation rate of PLGA matrices. Eur J Pharm Biopharm 2006;64:287-93.

28. Hillery A, Lloyd A, Swarbrick J. Drug delivery and targeting. London; New York, NY: Taylor and Francis Inc; 2005.

29. Derringer G, Suich R. Simultaneous optimization of several response variables. J Qual Technol 1980;12:214-9.

30. Iftikhar SY, Iqbal FM, Hassan W, Nasir B, Sarwar AR. Desirability combined response surface methodology approach for optimization of prednisolone acetate loaded chitosan nanoparticles and in vitro assessment. Mater Res Express 2020;7:1-10. 